Original article

\title{
REVERSAL OF EPIDURAL XYLAZINE IN EGYPTIAN WATER BUFFALO (BUBALUS BUBALIS) WITH ATIPAMEZOLE
}

\author{
M. M. SHOKRY ${ }^{1} \&$ A. H. ELKASAPY ${ }^{2}$ \\ ${ }^{1}$ Department of Surgery, Anaesthesiology and Radiology, Faculty of Veteri- \\ nary Medicine, Cairo University, Giza, Egypt; ${ }^{2}$ Department of Surgery, \\ Faculty of Veterinary Medicine, Benha University, Moshtohor, Egypt
}

\section{Summary}

Shokry, M. M. \& A. H. Elkasapy, 2021. Reversal of epidural xylazine in Egyptian water buffalo (Bubalus bubalis) with atipamezole. Bulg. J. Vet. Med., 24, No 3, 376-382.

The reversal of epidural xylazine, induced with IV atipamezole was evaluated in 15 buffaloes. Atipamezole at different dose rates $(5,10$ and $15 \mu \mathrm{g} / \mathrm{kg})$ injected 30 minutes after epidural xylazine provoked visible signs of arousal shortly after inection in all buffaloes without any side effects. The mean arousal times were $4.8 \pm 0.84 \mathrm{~min}, 2.4 \pm 0.24 \mathrm{~min}$ and $2.0 \pm 0.00 \mathrm{~min}$ while the mean total recovery times were $61.0 \pm 2.6 \mathrm{~min}, 33.0 \pm 3.7 \mathrm{~min}$ and $32.0 \pm 4.3 \mathrm{~min}$ following doses of 5,10 and $15 \mu \mathrm{g} / \mathrm{kg}$ atipamezole respectively. The heart, respiratory and ruminal rates were mildly influenced. Overall, the IV atipamezole at a dose rate of $10 \mu \mathrm{g} / \mathrm{kg}$ was found effective and satisfactory for reversing the analgesic, sedative and cardiopulmonary depression effects induced by epidural xylazine administration in buffaloes.

Key words: analgesia, atipamezole, buffalo, epidural, sedation, xylazine

\section{INTRODUCTION}

Buffaloes have great economic importance among food animals in Egypt and are frequently subjected to surgical and obstetrical procedures under epidural anaesthesia.

The alpha 2-agonists of veterinary importance are xylazine, detomidine, medetomidine and romifidine. The most important differences between these agonists are associated to their $\alpha 2 / \alpha 1$ selectivity and agonistic efficiency on $\alpha 2$ adrenoceptors (Lamminausta, 1991). Xylazine, detomidine, dexmedetomidine and medetomidine have demonstrated a potent analgesic effect when applied epidurally or intrathecally in different animal species (Sabbe et al., 1990). The $\alpha 2$ adrenergic antagonists are atipamezole, yohimbine and tolazine. Yohimbine is the old model $\alpha 2$ antagonist with relatively low selectivity and specificity. Tolazine is considered an unselective $\alpha$-blocker. Atipamezole is a highly selective $\alpha 2$ adrenergic antagonist of agonist sedation and the preferred compound (Lamminausta, 1991). These antagonists act by 
occupying and interacting with $\alpha 2$ adrenergic receptors, thus denying the $\alpha$ agonists access to these receptors. In the process they enhance the release of norepinephrine and other excitatory neurotransmitters (Mohammad, 1987; Brander et al., 1991).

Xylazine is a common $\alpha 2$-agonist sedative and analgesic drug used in ruminants (Gray \& McDonell, 1986; Short, 1992). It produces its analgesic and sedative effects by stimulating the $\alpha 2$-adrenergic receptors in the central nervous system while the muscle relaxant effect is based on inhibition of intraneural transmission of impulses in the central nervous system (Buerkle \& Yaksh, 1998). Xylazine is administered by different routes and it is administered epidurally to provide rapid onset and prolonged duration of aneasthesia in ruminants (Caron \& LeBlanc, 1989; Jean et al., 1990; Mohamed \& Liman, 1998; Grubb et al., 2002; Shokry \& Elkasapy, 2018). However, prolonged epidural xylazine duration might be accompanied with undesirable side effects such as cardiopulmonary depression, reduced ruminal motility and ataxia (Green \& Thurmon, 1988; Hall \& Clarke, 1991). In such conditions, an effective reversal with $\alpha 2$-adrenergic receptor antagonists such as yohimbine, tolazoline and atipamezole is prescribed (Bondke \& Kowollik, 1988; Komulainen \& Olson, 1991; Ko \& McGrath, 1995).

Atipamezole is the most potent and selective $\alpha 2$-adrenergic antagonist (Virtanen, 1989) and is currently used as an antidote for $\alpha 2$-agonist drugs in ruminants (Thompson et al., 1991; Arnemo \& Soli, 1993; Tiwari et al., 1998; Mpanduji et al., 2001). The objective of the present study was to determine the optimum dosage of atipamezole for reversal of epidural xylazine-induced sedation in the Egyptian water buffalo.

\section{MATERIALS AND METHODS}

\section{Animals}

A total of 20 healthy non-pregnant female Egyptian buffaloes (4-6 years of age, weighing between 500 and $600 \mathrm{~kg}$ ) from Benha University dairy farm were used in this study that started in June 2018 for 2 months. The study was approved by the Institutional Animal Care and Use Committee of Cairo University (IACUC). The animals were fasted for 12 hours prior to experimentation and allowed to drink $a d$ libitum. The animals were randomly assigned to 4 groups of 5 buffaloes each.

\section{Technique}

Each animal from all groups was secured in the stanchion and the skin over the sacrococcygeal area was aseptically prepared. An injection of $0.1 \mathrm{mg} / \mathrm{kg}$ xylazine (Xylaject 2\%; Adwia, Egypt) was made in the epidural space through the sacrococcygeal space. The total volume of xylazine, administered for each animal was fixed at $7.0 \mathrm{~mL}$ by adding $0.9 \%$ $\mathrm{NaCl}$. Observations of the clinical signs were then recorded. Thirty minutes after xylazine epidural injection, the IV injection of atipamezole $\mathrm{HCl}$ (Antisedan 5.0 $\mathrm{mg} / \mathrm{mL}$, Orion Pharma, Finland) was made into the jugular vein. The dose rates of atipamezole were $5 \mu \mathrm{g} / \mathrm{kg}, 10 \mu \mathrm{g} / \mathrm{kg}$ and $15 \mu \mathrm{g} / \mathrm{kg}$ for groups 1,2 and 3 respectively. The total volume of atipamezole for each animal was diluted by adding 0.9 $\mathrm{NaCl}$ (Normal saline $500 \mathrm{~mL}$; Otsuka Pharmaceutical Company, Egypt) and fixed at $5.0 \mathrm{~mL}$. Control group received only IV dose of $5.0 \mathrm{~mL}$ saline.

\section{Observations}

Observations were performed at 1-minute intervals until onset of xylazine epidural anaesthesia (occurrence of tail flaccidity 
and loss of response to pinpricks in the perineal region) and then at 5-minute intervals until the maximum effect was reached and defined as the time from injection to loss of sensation in the inguinal, upper thigh and sacral regions.

The pre-atipamezole (baseline) and the post-atipamezole injection rectal temperature $\left({ }^{\circ} \mathrm{C}\right)$, heart rate (beats/minute), respiratory rate (breaths/minute) and ruminal motility (contractions/2 minutes) values were recorded. Analgesia score was determined by assessment of response to pinprick in the perineal area and scored as: (0) no reaction, (1) mild reaction and (3) normal reaction. Sedation was scored as: (0) no sedation; (1) mild (slight lowering of the head and/or protrusion of the lower lip); (2) moderate (protrusion of the third eyelid, mydriasis and ptyalism); or (3) severe (leaning on stanchion for support). Analgesia and sedation scores were recorded at 10 minute intervals and up to 60 minutes. Ataxia was scored as: (0) absent; (1) mild (slight stumbling but able to walk); (2) moderate (marked stumbling and ataxia) or (3) severe (recumbency). Alertness was assessed according to the response to some acoustic reflexes with sudden noise to assess lifting of the head and ears reactions and also some visual reflexes to assess absence of ptosis, normal pupil size, pronounced eyeball movements, blinking of the eyelids and positive menace reflex.

The sedation-reversing effects of atipamezole were evaluated by recording the arousal time and total recovery time. Arousal time was defined as the time from the administration of atipamezole to the first signs of alertness, return of some of visual and acoustic responses and slight increase of both cardiopulmonary and ruminal motility values. Total recovery time was defined as the time from the ad- ministration of atipamezole to the stage of complete alertness and return of reflexes including normal drinking and eating. All observations were performed by a single observer who was unaware of treatment applied.

\section{Statistical analysis}

GraphPad Software (GraphPad-Prism Corp.) was used for statistical analysis. All data were analysed using the repeated measures one way ANOVA for comparison. Significance was set at $\mathrm{P}$ values less than 0.05 .

\section{RESULTS}

Caudal epidural xylazine anesthesia (0.1 $\mathrm{mg} / \mathrm{kg}$ ) produced satisfactory analgesia of the tail and perineum of standing buffaloes, combined with a desirable level of sedation (ptyalism, drooping of the head and eyelids, protrusion of the third eyelid). The onset of signs and the maximum effect occurred within 10 and 20 minutes of administration respectively. Rectal temperature, heart rate, respiratory rate and ruminal motility showed slight reduction (Figs. 1-4). None of the buffalo experienced severe sedation or ataxia or showed spontaneous recoveries before administra-

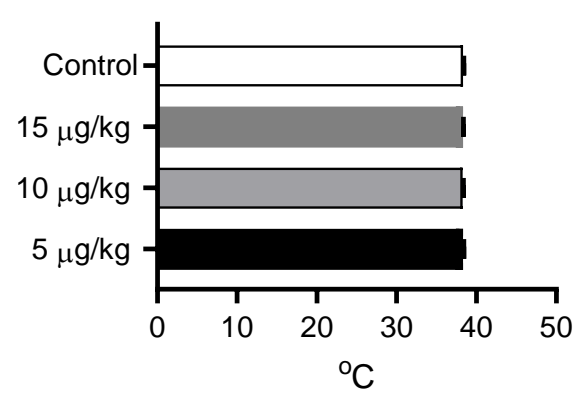

Fig. 1. Rectal temperature $\left({ }^{\circ} \mathrm{C}\right)$ in water buffaloes, treated with different doses of atipamezole $(5,10$ or $15 \mu \mathrm{g} / \mathrm{kg})$ and untreated controls. Data are presented as mean $\pm S E M ; n=5$. 


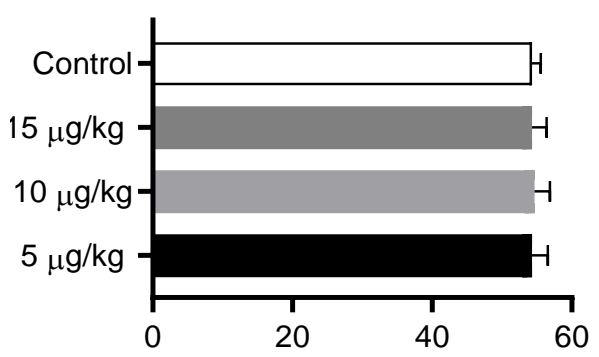

$\min ^{-1}$

Fig. 2. Heart rate $\left(\mathrm{min}^{-1}\right)$ in water buffaloes, treated with different doses of atipamezole (5, 10 or $15 \mu \mathrm{g} / \mathrm{kg}$ ) and untreated controls. Data are presented as mean $\pm S E M ; n=5$.

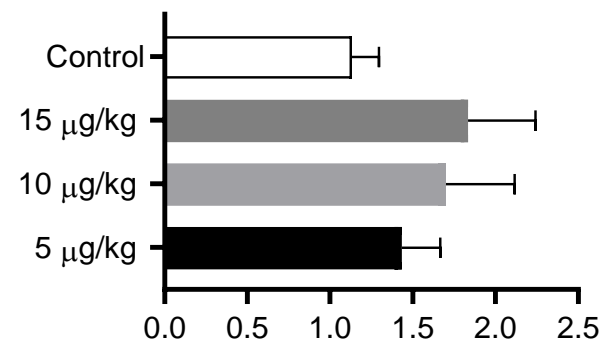

Fig. 4. Rumen motility (contractions/2 min) in buffaloes, treated with different doses atipamezole $(5,10$ or $15 \mu \mathrm{g} / \mathrm{kg})$ and untreated controls. Data are presented as mean $\pm S E M ; n=5$.

tion of atipamezole. Intravenous administration of atipamezole at different dose rates provoked visible signs of arousal shortly after injection expressed by acoustic and visual alertness combined with mild increase in the cardiopulmonary and rumen motility values while the rectal temperature was not affected.

The signs of recovery as lifting of the head, absence of ptyalism, ptosis and protrusion of the third eyelids and blinking of the eyelids were gradually recorded (Figs. $5 \& 6)$. The mean arousal times following 5,10 and $15 \mu \mathrm{g} / \mathrm{kg}$ atipamezole were $4.8 \pm$ $0.84 \mathrm{~min}, 2.4 \pm 0.24 \mathrm{~min}$ and $2.0 \pm 0.00 \mathrm{~min}$

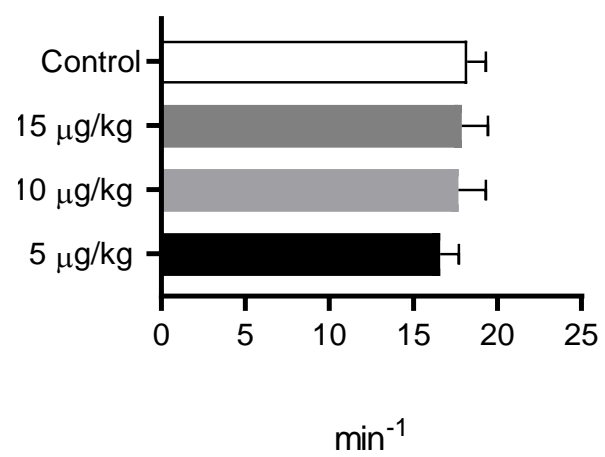

Fig. 3. Respiratory rate $\left(\mathrm{min}^{-1}\right)$ in water buffaloes, treated with different doses of atipamezole $(5,10$ or $15 \mu \mathrm{g} / \mathrm{kg})$ and untreated controls. Data are presented as mean $\pm S E M ; n=5$.

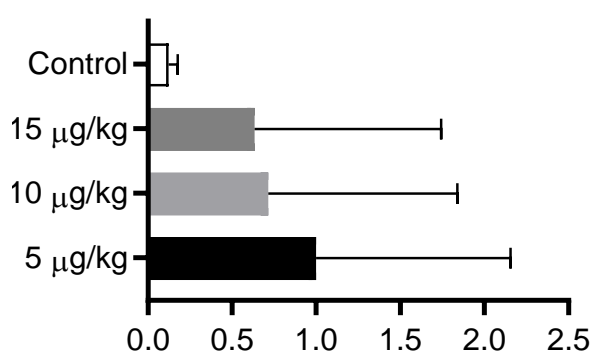

Fig. 5. Analgesia scores in water buffaloes, treated with different doses of atipamezole (5, 10 or $15 \mu \mathrm{g} / \mathrm{kg}$ ) and untreated controls. Data are presented as mean \pm SEM; $n=5$.

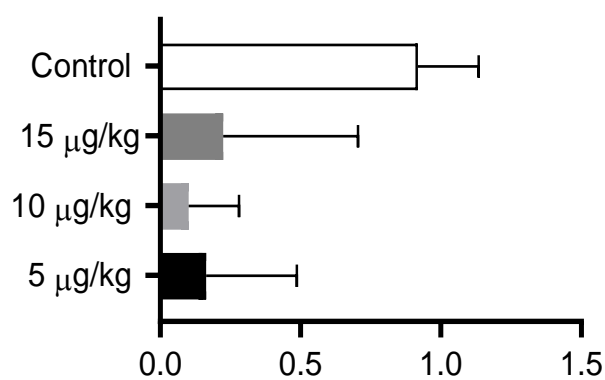

Fig. 6. Sedation scores in water buffaloes, treated with different doses of atipamezole $(5$, 10 or $15 \mu \mathrm{g} / \mathrm{kg}$ ) and untreated controls. Data are presented as mean \pm SEM; $n=5$. 
respectively while the mean total recovery times were $61.0 \pm 2.6 \mathrm{~min}, 33.0 \pm 3.7 \mathrm{~min}$ and 32.0 $\pm 4.3 \mathrm{~min}$, respectively (Fig. 7).

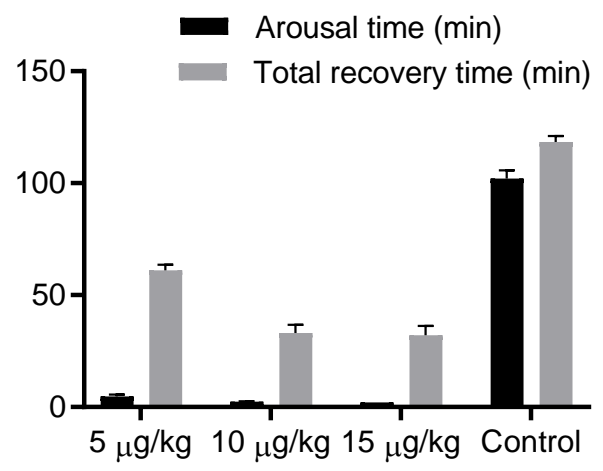

Fig. 7. Arousal and total recovery times (min) in water buffaloes, treated with different doses of atipamezole $(5,10$ or $15 \mu \mathrm{g} / \mathrm{kg})$ and untreated controls. Data are presented as mean \pm $\mathrm{SEM} ; \mathrm{n}=5$.

\section{DISCUSSION}

Epidural xylazine at $0.1 \mathrm{mg} / \mathrm{kg}$ through the sacrococcygeal space was satisfactory to induce adequate analgesia and moderate sedation. This is in agreement with a previous study using the same dose rate (Shokry \& Elkasapy, 2018). Atipamezole at 5,10 and $15 \mu \mathrm{g} / \mathrm{kg}$ reversed xylazineinduced epidural analgesia in buffaloes after IV administration without any side effects. The IV administration of atipamezole at $10 \mu \mathrm{g} / \mathrm{kg}$ was the optimal dose rate for rapid reversal of sedation in buffaloes with mean arousal time $2.4 \pm 0.24 \mathrm{~min}$ and total recovery time $33.0 \pm 3.7 \mathrm{~min}$. Atipamezole at 10 or $15 \mu \mathrm{g} / \mathrm{kg}$ induced almost similar antagonistic effect and was superior over the dose $5 \mu \mathrm{g} / \mathrm{kg}$ which caused delay in the mean total recovery time $(61.0 \pm 2.6 \mathrm{~min})$. A similar dose rate of atipamezole $(10 \mu \mathrm{g} / \mathrm{kg})$ was used to completely reverse the clinical and physiological effects of xylazine $(0.1 \mathrm{mg} / \mathrm{kg})$ in buffaloes (Tiwari et al., 1998). However, medetomidine-induced sedation has been optimaly reversed with atipamezole at the same or twice the dose of the agonist in lambs (Ko \& McGrath, 1995) at 4 to 6 times the dose in dogs (Vaha-Vahe, 1990) at 2 to 3 times the dose in cattle (Arnemo \& Soli, 1995) at 6-, 8- and 10fold doses in horses (Ramseyer et al., 1998) and at $80 \mu \mathrm{g} / \mathrm{kg}$ in goats (Mpanduji et al., 2001). Nevertheless, IV administration of $200 \mu \mathrm{g} / \mathrm{kg}$ atipamezole failed to reverse analgesia attributed to lumbosacral epidural injection of xylazine in pigs, but reversed both analgesia and cardiopulmonary depression effects induced by detomidine in the same species (Ko et al., 1992). Hence, the dosage recommendations for atipamezole vary among animal species and for various $\alpha 2$-agonists for small and zoo animals (Jalanka \& Roeken, 1989; Vaha-Vahe, 1990; Stauffer,1991).

In the present study, the effect of 10 or $15 \mu \mathrm{g} / \mathrm{kg}$ IV atipamezole was visible within 2 minutes and fully effective after 5-10 minutes in all animal trials. The heart and respiratory rates and ruminal motility showed gradual slight increases. However, no marked effect was demonstrated on the rectal temperature. Almost similar effects have been observed in cattle (Arnemo \& Soli, 1993), sheep (Mohammad et al., 1995; Bryant et al., 1996) and goats (Mpanduji et al., 2001).

Analgesia and sedation were rapidly reversed by IV administration of $10 \mu \mathrm{g} / \mathrm{kg}$ atipamezole with mean total recovery time $(33 \pm 3.7 \mathrm{~min})$, as evidenced by the rapid return of reflexes (acoustic and visual), absence of sedation signs and restoration of reaction to nociceptive stimulation and the ability to drink and eat. Recovery was complete without any signs of resedation or side effects. Similar observations have been reported in buffaloes (Tiwari et al., 
1998). However, heavy re-sedation with relapse was reported when low doses of atipamezole were used in dairy calves (Thompson et al.,1991).

\section{CONCLUSION}

The IV atipamezole at a dose rate of 10 $\mu \mathrm{g} / \mathrm{kg}$ was found effective and satisfactory as $\alpha 2$-adrenergic antagonist in reversing analgesia, sedation and cardiopulmonary depression effects induced by epidural xylazine administration in buffaloes.

\section{REFERENCES}

Arnemo, J. M. \& N. E. Soli, 1993. Chemical capture of free ranging cattle: Immobilization with xylazine or medetomidine, and reversal with atipamezole. Veterinary Research Communications, 17, 469-477.

Brander G.C., D. M. Pugh, R. J. Bywater \& W.L. Jenkins, 1991. Veterinary Applied Pharmacology and Therapeutics, $5^{\text {th }}$ edn, Baillière Tindall, London.

Brondke, D. \& N. Kowollik, 1988. Xylazine antagonist in animals: A review of the clinical aspects. Veterinary Medical Review, 59, 108-119.

Bryant, C. E., K. W. Clarke \& J. Thompson, 1996. Cardiopulmonary effects of medetomidine in shee and ponies. Research in Veterinary Science, 60, 267-271.

Buerkle, H. \& T. L. Yaksh, 1998. Pharmacological evidence for different alpha-2 adrenergic receptor sites mediating analgesia and sedation in the rat. British Journal of Anaesthesia, 81, 298-315.

Caron, J. P. \& P. H. LeBlanc, 1989. Caudal epidural analgesia in cattle using xylazine. Canadian Journal Veterinary Research, 53, 486-489.

Gray, P. R. \& W. N. McDonell, 1986. Anaesthesia in goats and sheep. Part I. Local analgesia. Compendium on Continuing Edu- cation for the Practising Veterinarian, 8 , 33-38.

Green, S. A. \& J. C. Thurmon, 1988 Xylazine: A review of its pharmacology and use in veterinary medicine. Journal of Veterinary Pharmacology and Therapeutics, 11, 295-313.

Grubb, T. L, T. W. Riebold \& R. O. Crisman, 2002. Comparison of lidocaine, zylazine, and lidocaine-xylazine for caudal epidural analgesia in cattle. Veterinary Anaesthesia and Analgesia, 29, 64-68.

Hall, L.W. \& K. W. Clarke, 1991.Veterinary Anaesthesia, $9^{\text {th }}$ edn, Baillière Tindall, London.

Jalanka, H. \& B. O. Roeken, 1990. The use of medetomidine, medetomidine-ketamine combinations, and atipamezole in nondomestic mammals: A review. Journal of Zoo and Wildlife Medicine, 21, 259-282.

Jean, G., R. T. Skarda, W. W. Muir \& G. F. Hoffsis, 1990. Caudal epidural analgesia induced by xylazine administration in cows. American Journal of Veterinary Research, 51, 1232-1236.

Ko, J. C. H., J. C. Thurmon, J. G. Benson, W. J. Tranquilli \& W.A. Olson, 1992. Evaluation of analgesia induced by epidural injection of detomidine or xylazine in swine. Veterinary Anaesthesia, 19, 56-60.

Ko, J. C. H. \& J. C. McGrath, 1995. Effects of atipamezole and yohimbine on medetomidine-induced central nervous system depression and cardiorespiratory changes in lambs. American Journal of Veterinary Research, 56, 629-632.

Komulainen, A. \& M. E. Olson, 1991. Antagonism of ketamine-xylazine anaesthesia in rats by administration of yohimbine, tolazoline or 4-aminopyridine. American Journal of Veterinary Research, 52, 585-588.

Lammintausta, R., 1991. The alpha-2 adrenergic drugs in veterinary anaesthesia. In: Proceedings of the $4^{\text {th }}$ International Congress of Veterinary Anaesthesia, pp. 3-8. 
Mohamed, A. \& M. Liman, 1998. Xylazine (Chanazine*) as an epidural anaesthetic agent in sheep. Small Ruminant Research, 27, 85-87.

Mohammad, F. K., I. K. Zangana \& A. R. Abdul-Latif, 1995. Reversal of medetomidine sedation in sheep by atipamezole and yohimbine. Veterinary and Human Toxicology, 37, 97-99.

Mohammad, F. K, 1987. Xylazine antagonists in animals: A review of pharmacological aspects. Veterinary Medical Review, 1, 3-8.

Mpanduji, D. G., S. B. P. Bittegeko, E. K. Batamuz, M. N. Magasa \& C. L. Shami, 2001. Comparison of the effects of atipamezole and tolazoline on analgesia,cardiopulmonary and rectal temperature changes induced by lumbosacral epidural injection of medetomidine in goats. Small Ruminant Research, 40, 117-122.

Ramseyer, B., N. Schucker, U. Schatzmann, A. Busato \& Y. Moens, 1998. Antagonism of detomidine sedation with at atipamezole in horses. Journal of Veterinary Anaesthesia, 25, 47-51.

Sabbe, M. B., J. P. Penning \& T. L. Yaksh,1990. Antinociception and $\mathrm{CO}_{2-}$ response following spinal and systemic dexmedetomidine in dogs. Anesthesiology, 73, (Abstracts), A1269.

Shokry, M. M. \& A. H. Elkasapy, 2018. Epidural anaesthesia in Egyptian water buffalo (Bubalus bubalis): A comparison of lidocaine, xylazine and a combination of lidocaine and xylazine. Veterinary Anaesthesia and Analgesia, 45, 707-710.

Short, C. E., 1992. Alpha 2-agents in Animals: Sedation, Analgesia and Anaesthesia. Veterinary Practice Publishing Company, Santa Barbara, CA, USA.
Stauffer, J. L., H. Steger, G. Walter, C. Gaillard \& U. Schatzmann, 1991. Reversal of medetomidine sedation-analgesia by atipamezole in dogs. In: Proceedings of $4^{\text {th }}$ International Congress of Veterinary Anaesthesia, pp. 75-76.

Thompson, J. M., K. W. Kersting \&W. H. Hsu, 1991. Antagonistic effect of atipamezole on xylazine-induced sedation, bradycardia and ruminal atony in calves. American Journal of Veterinary.Research, $\mathbf{5 2}$, 1265-1268.

Tiwari, S. K., A. Kumar \& O. Vainio,1998. Reversal of sedative and clinicophysiological effects of epidural xylazine and detomidine with atipamezole and yohimbine in buffaloes (Bubalus bubalis). The Veterinary Record, 143, 529-532.

Vaha-Vahe, A. T., 1990. Clinical effectiveness of atipamezole as a medetomidine antagonist in dogs. Journal of Veterinary Pharmacology and Therapeutics, 13, 198-205.

Virtanen, R., 1989. Pharmacological profiles of medetomidine and its antagonist, atipamezole. Acta Veterinaria Scandinavica, 85, 29-37.

Paper received 12.09.2019; accepted for publication 30.11.2019

\section{Correspondence:}

M. M. Shokry

Department of Veterinary Surgery,

Faculty of Veterinary Medicine,

Cairo University,

Giza 12211, Egypt,

phone:+201068993788

e-mail:mshokry@cu.edu.eg 